\title{
Relationships between Return of Stock Price Index and Interest Rate
}

\section{Jiajia Chen}

\author{
Shanghai Academy, Shanghai University, No.149, Yanchang Road, Jingan District, Shanghai, \\ China \\ cherrycjjsh@163.com
}

\section{Keywords: Stock market volatility; Interest rate; GARCH model}

\begin{abstract}
The stock market has an increasingly significant impact on China's macro economy, but the risk and volatility of the stock market itself has also received more attention. How to prevent stock market risk is also one of the important topics of government work. Interest rate is one of policies and this factor can affect the price of the stock. This article selects the yield rate which comes from the Shanghai Stock Exchange and the interbank lending rate which comes from Shanghai Bank. The ARMA model was established based on the returns from the Shanghai Stock Exchange Index and the GARCH model was established using Shanghai Bank's interbank lending rate. Finally, using the Granger test, we conclude that there is a long-term co-integration relationship between the two, but the causal relationship is not obvious.
\end{abstract}

\section{Introduction}

With the continuous improvement of the degree of marketization in China, stocks have both influence and relation to the economy. The role of the stock market in the barometer of the market economy is obvious. At the same time, the stock market has strong risks and volatility. The collapse of the stock market has also become a major feature of the financial crisis that has erupted in emerging countries in the past 30 years. The government needs to take good measures to solve problems. It is very important. At present, there are many factors that affect stock prices. The adjustment of the benchmark interest rate by the People's Bank of China is a topic that has been a constant concern in the financial sector

The stock price index is a comprehensive reflection of the operation of the stock market and interest rates also has very important significance for the currency market and is one of the important means of monetary policy regulation [1]. The weakening of financial regulation in recent years has also led to the strengthening of information and capital flows between money markets and financial markets. The link between interest rates and stock price indices has also been continuously strengthened. On the one hand, interest rates can change the financing costs of enterprises. The decline in interest rates can improve the business environment of enterprises, reduce business risks, and increase the profitability of enterprises. On the other hand, savings and interest rates are an alternative relationship. As a result, the proportion of assets will be greatly changed due to this factor. Finally, from the perspective of behavioral finance, investors are expected to change due to changes in interest rates, triggering shocks in the stock market. To research the relationship between both of them is meaningful for investigators when investigating and helpful to policies' makers.

\section{Summary of the Theory}

The introduction of two models is as follows. The ARMA model is called the auto regression moving average model and is the most commonly used model for fitting stationary sequences. It can be also subdivided into three categories: auto regression model, MA moving average model and ARMA regression model. The GARCH Model can not only describe the sustainability of the model regression residuals, but also can reflect the volatility of financial time series and the aggregation characteristics of variables. In 1982, the American economist Engle proposed the GARCH model .Variances in the variance over time can be demonstrated by the model. The basic idea is at time $t$. The variance of the model error term depends on the square of the actual error of the model 
in the previous t-1. In 1986, Bollerslev extended the ARCH model to a more widely used GARCH model. AIC and SC are the criteria for evaluating whether the model is excellent. This indicator can evaluate whether the estimated model fitting data is good and complex. AIC $=2 \mathrm{k}-2 \ln \mathrm{L}$ and the $\mathrm{k}$ represents the number of parameters and L represents the likelihood function [2]. Generally speaking, it is better to choose which model is better. Generally, the value of the two is smaller, so it can be regarded as excellent.

The Definition and Development of CO-integration is as follows. In real life, although some sequences are not stable in terms of their own changes, long-term equilibrium relations occur between them. So in order to measure their relationship, Engle and Granger proposed the concept of co-integration in 1987. Construct a regression model:

$$
\mathrm{y}_{\mathrm{t}}=\beta_{0}+\sum_{i=1}^{k} \beta_{i} \mathrm{x}_{\mathrm{it}}+\varepsilon_{\mathrm{t}} .
$$

The key to whether or not a dynamic regression model can be established between multiple non-stationary sequences is whether there is a co-integration relationship between them. So the first step in co-integration testing is how far a non-stationary sequence is in the modeling process.

Granger Causality Test. The Granger test used to analyze the Granger causality between economic variables can be defined as "The variance of the best least squares prediction is dependent on the use of information at some point in time." A Prerequisite for the Granger Test The condition is that the time series must have smoothness, otherwise false return may occur [3]. Granger test results can be divided into four situations: affects $y$, and $\mathrm{x}$ has a one-to-one relationship with $\mathrm{y} ; \mathrm{y}$ affects $\mathrm{x}$, $\mathrm{y}$ has a one-to-one relationship with $\mathrm{x}$; $\mathrm{x}$ and $\mathrm{y}$ interact with each other; There is no relationship between $\mathrm{x}$ and $\mathrm{y}$ [4].

Stock Price Index. The stock price index is an indicator that reflects the overall price level of the stock market and its movements. It is referred to as the stock price index. It is calculated by selecting a representative group of stocks and weighting the average. The major stock price indices in China include the Shanghai Composite Index, the Shenzhen Composite Index, the Shanghai Composite Index, the Shenzhen Composite Index and the Shanghai and Shenzhen Stock Index [5]. The index selected by the stock price index of this article is the Shanghai Stock Exchange Index, which has high market value coverage, wide industry distribution, and high liquidity, which can better reflect the price level and fluctuation of the entire market. Measure the yield of daily stocks in logarithmic form of the yield, using the formula $R_{t}=\ln \left(P_{t}\right)-\ln \left(P_{t-1}\right)$ Amongthem, $R_{t}$ representing the yield on the $t$-day stock index, $P_{t}$ represents the closing price of each stock index on $\mathrm{t}$.

Inter-bank Offered Rate. The determination of Shanghai inter-bank interbank lending rate is based on banks with high credit ratings. The rate they quoted for inter-bank RMB interbank offerings is a standard, which is an unsecured, wholesale interest rate. At present, there are overnight, one week, two weeks, one month, three months, six months, nine months and one year for the public [6]. Its on-line operational time was January 4, 2007. SHIBOR's currency market benchmark interest rate status has been initially established. Its trend has relatively clear reflections on the implementation of macro-control policies, and the correlation with other interest rates has continued to increase, and the important role in the transmission channels of monetary policy has been further manifested. This article mainly selects overnight SHIBOR as an indicator of market interest rates.

\section{Empirical Analysis}

The Selection of Variables is as follows. To study the relationship between the interest rate and the return of the stock price index, the two types of fluctuations, this article selected the SHIBOR from January 4, 2007 to February 24, 2017 and calculated the stock returns of the Shanghai Stock Exchange Index, a total of 2466 data. The data comes from the Wind database.

The Basic Statistical Characteristics are as follows. First, the statistical descriptions of the yield ratios of the Shanghai Stock Exchange Index and Bank of Shanghai and the interbank offering 
rate are separately described. The results are shown in Table 1 below.

Table 1 Basic Statistics of Shanghai Stock Index Returns and SHIBOR

\begin{tabular}{lcrrrc}
\hline variable & Mean & $\begin{array}{c}\text { Standard } \\
\text { deviation }\end{array}$ & $\begin{array}{c}\text { Partial } \\
\text { degree }\end{array}$ & Kurtosis & JB \\
\hline $\begin{array}{l}\text { Shanghai } \\
\text { Stock Index }\end{array}$ & $7.26 \mathrm{e}-0.5$ & 0.0178 & -0.6102 & 6.796 & 1633.713 \\
SHIBOR & 2.328 & 1.009 & 2.006 & 13.791 & 13619.02 \\
\hline
\end{tabular}

From Table 1, we can see that the average yield of the Shanghai stock index is $7.26 \mathrm{e}-0.5$, the standard deviation is 0.0178 , and the partial degree is -0.6102 , which means that the yield is left to a certain extent, and the kurtosis is 6.796 far greater than 3, indicating that Significant spike characteristics. The mean value of SHIBOR was 2.328 and the standard deviation was 1.009 . It had a certain degree of discrepancies. The partial degree was 2.006>0, and there was a certain degree of rightward deviation. The kurtosis was 13.791, which was much larger than 3 , indicating significant spike characteristics. The normality testing of the two JB statistics were 1633.713 and 13619.02, respectively, and they refused to obey the assumption of normal distribution. The statistical analysis of these data shows that the stock index returns and SHIBOR are not normally distributed and have a spike character.

Shanghai Stock Index Yield ARMA Model. Smoothness test: The ADF test is required for smoothness testing of the Shanghai Composite Index, $\mathrm{p}=0.0001$, and the test statistic is significantly lower than the critical value at the 5\% significance level, indicating that the sequence is stable.

Table 2 ADF test results

\begin{tabular}{r|r|r|r}
\hline & t-Statistic & Prob. $^{*}$ \\
\hline \multicolumn{2}{c|}{ Augmented Dickey-Fuller test statistic } & -48.73578 & 0.0001 \\
\hline Test critical values: & $1 \%$ level & -3.432809 & \\
\hline & $5 \%$ level & -2.862512 & \\
\hline & $10 \%$ level & -2.567333 & \\
\hline
\end{tabular}

Pure Randomness Test -The pure randomness test (white noise test) is used to test if the model of the sequence is necessary. The test to test the pure randomness of the sequence requires the use of the LB statistic.

Table $3 \mathrm{Q}_{\mathrm{LB}}$ Statistics Test

\begin{tabular}{ccc}
\hline & $\mathrm{Q}_{\mathrm{LB}}$ Statistical test & P value \\
\hline Delay 6 & 26.985 & 0.01 \\
Delay 12 & 31.450 & 0.002
\end{tabular}

The result shows that the confidence level is 95 percent. Therefore, the original hypothesis is rejected and the sequence is considered as a non-white noise sequence. The sequence can be further statistically analyzed.

Establish an ARMA model- According to the autocorrelation graphs and partial autocorrelation graphs of the SSE stock index return rate, it is found that the autocorrelation coefficient and partial autocorrelation coefficient of the Shanghai Stock Index return series have a tailing phenomenon. You can try to fit the ARMA model. 

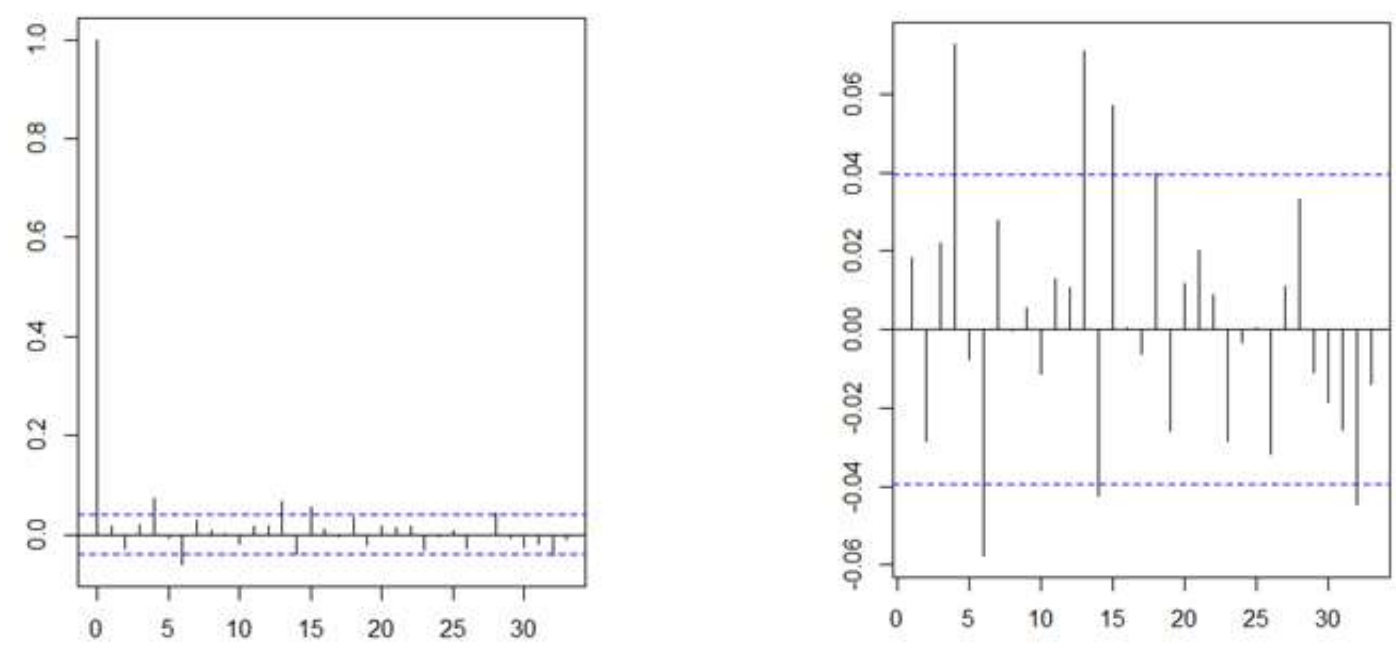

Figure 1. Finite Shanghai Composite Index's yield autocorrelation plot and partial correlation plot

According to the significance of the regression coefficients and the AIC and BIC criteria, the fitting results of the ARMA $(3,2)$ model are found to be optimal. The model formula is:

$$
\mathrm{R}_{\mathrm{t}}=\emptyset_{1} \mathrm{R}_{\mathrm{t}-1}+\emptyset_{2} \mathrm{R}_{\mathrm{t}-2}+\emptyset_{3} \mathrm{R}_{\mathrm{t}-3}+\theta_{1} \varepsilon_{\mathrm{t}-1}+\theta_{2} \varepsilon_{\mathrm{t}-2}+\varepsilon_{\mathrm{t}}
$$

The ARMA $(3,2)$ results of the stock index yield are shown in the table below:

Table 3 ARMA $(3,2)$ parameter estimation results

\begin{tabular}{ccc}
\hline coefficient & Coefficient value & Standard error \\
\hline$\emptyset_{1}$ & 0.194 & 0.066 \\
$\emptyset_{2}$ & -0.86 & 0.10 \\
$\emptyset_{3}$ & 0.049 & 0.024 \\
$\theta_{1}$ & -0.175 & 0.063 \\
$\theta_{2}$ & 0.82 & 0.12 \\
\hline
\end{tabular}

It can be seen that the regression coefficients are significant in this equation. The yield of the t-period of the Shanghai stock index is affected by the yield of the third-phase lag period and the prediction error of the second-phase lag period. It also has positive effect in the first-phase and third-phase lag periods and negative effect in the second-phase lag periods.

The Model Significance Test - The significance test of the ARMA $(3,2)$ model shows that the test results cannot reject the original hypothesis, that the fitting model is valid, and that the information in the sequence is more adequately extracted.

SHIBOR and GARCH Model are follows. Residual squares purely random acoustic test: If there is no pure randomness test for the residual squared, there is useful information in the residual, which needs further processing. The pure randomness test of the squared residuals yields $\mathrm{p}=0$, so the squared residual is a non-white noise sequence, indicating that there is some autocorrelation in the residual sequence.

ARCH test-QQ graph: The normal QQ graph of the Shanghai Composite Index's yield series is shown in the chart below. From the QQ graph's low quintile and high quintile (ie, the tail of the graph curve), we can see that the sequence has a heavy tail which indicating that there are extreme values in the sequence, does not meet the homogeneity of variance. 


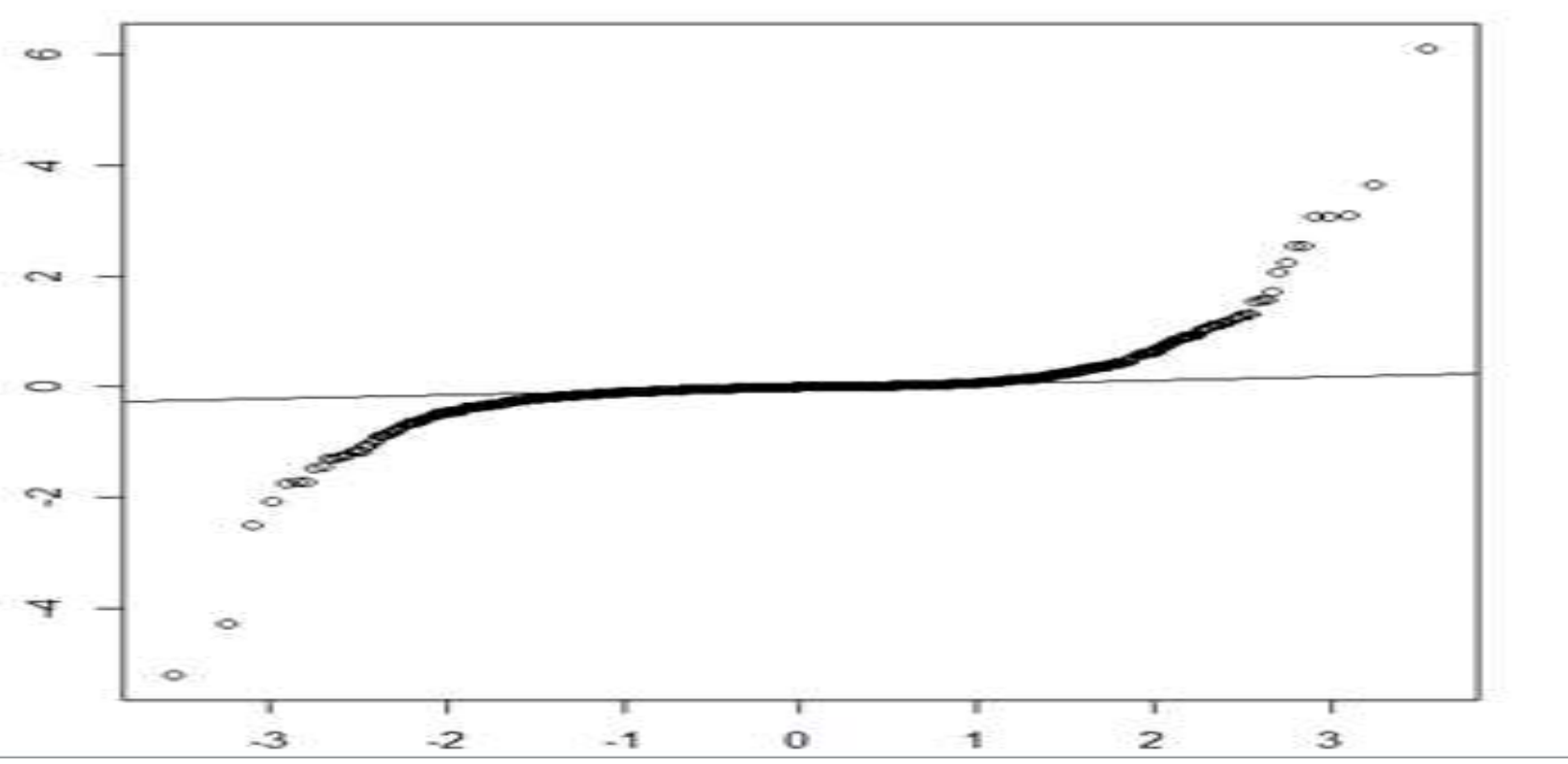

Figure 2. Finite QQ

LM test-The ARCH test was performed using the LM test. The results showed that the original hypothesis was rejected at the level of 5\% significance. The residual of the sequence was considered to have an autocorrelation relationship and it had an $\mathrm{ARCH}$ effect.

Heteroskedasticity Test: ARCH

\begin{tabular}{llll}
\hline \hline F-statistic & 284.1702 & Prob. F(2,2460) & 0.0000 \\
Obs*R-squared & 462.2408 & Prob. Chi-Square(2) & 0.0000 \\
\hline \hline
\end{tabular}

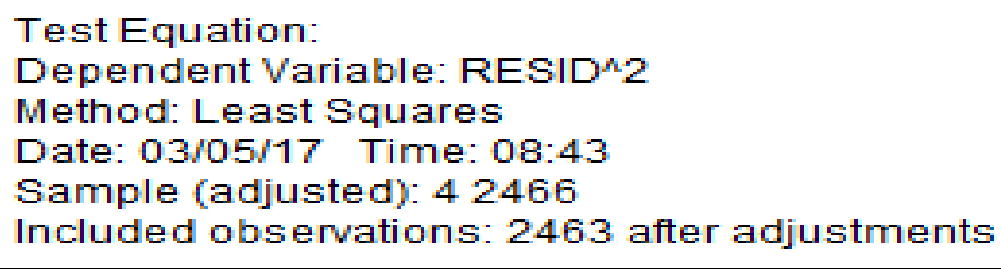

\begin{tabular}{lrlrr}
\hline \hline & Coefficient & Std. Error & t-Statistic & Prob. \\
\hline \hline \multicolumn{1}{c}{ C } & 0.076339 & 0.020943 & 3.645006 & 0.0003 \\
RESID 2(-1) & 0.464389 & 0.020075 & 23.13238 & 0.0000 \\
RESID 2(-2) & -0.092619 & 0.020075 & -4.613590 & 0.0000 \\
\hline \hline R-squared & 0.187674 & Mean dependent var & 0.121516 \\
Adjusted R-squared & 0.187013 & S.D. dependent var & 1.143733 \\
S.E. of regression & 1.031256 & Akaike info criterion & 2.900649 \\
Sum squared resid & 2616.183 & Schwarz criterion & 2.907725 \\
Log likelihood & -3569.150 & Hannan-Quinn criter. & 2.903220 \\
F-statistic & 284.1702 & Durbin-Watson stat & 1.976211 \\
Prob(F-statistic) & 0.000000 & & \\
\hline \hline
\end{tabular}

Figure 3. Finite ARCH effect test results

Establish SHIBOR GARCH model- According to the significance of the regression coefficients and the AIC and BIC criteria, the regression coefficients of the models GARCH $(1,2)$ and GARCH $(2,1)$ were found to be insignificant. Therefore, the GARCH $(1,1)$ model can be used to best fit the 
Shanghai Stock Exchange the characteristics of stock index volatility, the fitting result is:

$$
\left\{\begin{aligned}
\mathrm{x}_{\mathrm{t}}= & 0.000198+0.514432 \mathrm{x}_{\mathrm{t}-1}-0.697266 \mathrm{x}_{\mathrm{t}-2}+0.042700 \mathrm{x}_{\mathrm{t}-3}+\varepsilon_{\mathrm{t}}+0.500138 \varepsilon_{\mathrm{t}-1}- \\
& 0.675932 \varepsilon_{\mathrm{t}-2} \\
\varepsilon_{\mathrm{t}}= & \sqrt{\mathrm{h}_{\mathrm{t}} * \mathrm{v}_{\mathrm{t}}} \\
\mathrm{h}_{\mathrm{t}}= & 0.000001+0.947463 \mathrm{~h}_{\mathrm{t}-1}+0.050757 \varepsilon_{\mathrm{t}-1}{ }^{2}
\end{aligned}\right.
$$

Residual ARCH test-Perform. (a) Co-integration analysis: Co-integration tests were performed on the two sequences, but since the SHIBOR is only stationary after the first-order difference, the Shanghai Composite Index itself is a stationary sequence, so these two sequences cannot be co-integrated. (b) Granger causality test. The relationship between the interest rate and the stock market is the most basic. The study of whether the two are related is the use of Granger. The Granger test results can help predict the impact of interest rates on the securities market.

The following figure shows the results of the Granger test using e-views software regression.

Table 4 Granger test results

\begin{tabular}{lllllll}
\hline & Lag1 & Lag2 & Lag3 & Lag4 & Lag5 & Lag6 \\
\hline & P 值 & P 值 & P 值 & P 值 & P 值 & P 值 \\
\hline $\begin{array}{l}\text { does not Granger } \\
\text { Cause SHIBOR }\end{array}$ & 0.8261 & 0.9291 & 0.6447 & 0.6071 & 0.6166 & 0.7326 \\
\hline $\begin{array}{l}\text { SHIBOR does } \\
\text { not Granger }\end{array}$ & 0.1966 & 0.4627 & 0.2179 & 0.2697 & 0.2881 & 0.3700 \\
Cause SZ & & & & & \\
\hline
\end{tabular}

The above table shows that the Granger causality test between these two variables is not obvious. The result may be that the SHIBOR interest rate system has just been established in 2007, and China's previous implementation of the interest rate control policy has led to a non-smooth transmission mechanism in the interest rate market, and the market situation has no obvious reflection. China's securities market has only just begun in 1990. Compared with the maturity of foreign securities markets, the mechanism of China's securities market is still not perfect and is affected by many risk factors, making the leverage effect of interest rates offset by other factors[7].

\section{Conclusions and Suggestions}

The Conclusions are as follows. Through comparative analysis of the yield and interest rate of the Shanghai Composite Index ARMA and GRACH model, the following conclusions are drawn:

1. The data meets the smoothness test after being processed, and the characteristics of spikes, thick tails, and clustering are more obvious.

2. The yield rate of the Shanghai stock index is suitable for the establishment of the ARMA $(3,2)$ model. Its yield is affected by the lag period, and the positive and negative influences brought by different lag periods are quite different. SHIBOR needs to be differentiated because there is autocorrelation and the difference follows the model $\operatorname{ARMA}(1,2)$.

3. ARCH effects exist in both sequences After the ARMA model is established, the AIC value after comparing $\operatorname{GARCH}(1,1)$ is the smallest, so the volatility of the yield and interest rate of the Shanghai Stock Index can be predicted by $\operatorname{GRACH}(1,1)$. .

4. The Granger causality test found no significant causal relationship between the two. The analysis may be due to the fact that in real economic activities, in addition to interest rates, there are many factors that will make the stock market in a state of change, in the study of interest rate adjustment While the influence of the stock market, other factors are also affecting the stock market, such as people's expectations and so on. Therefore, one cannot only look at the interest rate factor. On the other hand, the public is expected to be able to digest the effect of interest rate adjustment in advance. This is the result of the failure of the "Lucas" policy. The more important aspect is the late 
start of China's securities market and interest rate market, the immature development, and the transfer of interest rate adjustments in the stock market. The mechanism could not be effectively implemented. Even if the SHIBOR was established, the interest rate in our country was not fully market-based the interest rate could not reflect the degree of scarcity of funds. Due to the market's non-marketization restrictions, the equilibrium interest rate in the capital market could not be realized, and there were other various factors. It has made it difficult for investors to make investment decisions [8].

5. In the long run, there is an equilibrium relationship between stock index returns and interest rates [9].

Suggestions are as follows. Interest rate is one of the important policies in monetary policy. The monetary authorities should take the following measures:

1. Continue to liberalize the stock market, less reduce human intervention, and continue to advance the reform of interest rate liberalization. As the degree of marketization becomes higher and higher, and as the social financial system becomes more mature, the relationship between interest rates and the stock market will become more and more closed [10]. Changes and shocks between markets will occur in succession. If the government can understand how the mechanisms between them are transmitted, it will better control and prevent risks.

2. The monetary authorities should adopt different policies from the long-term and short-term perspectives, focusing on the overall macro economy. And consider the impact of lags on policies, carefully policy reduces the extent of unnecessary intervention to bring about long-term effects.

3. Because China's interest rate adjustment will always give off sound in advance, and social groups can better adapt to the implementation policy, interest rates cannot have a significant impact on the stock market [11]. When governments and policies formulate policies, they should do a good job of keeping confidential measures in advance and inadvertently give exogenous shocks so that they can have effective impact.

\section{References}

[1] X.L. Dai. Empirical Analysis of Effect of Interest Rate Changes on Daily Returns and Volatility of Shanghai Stock Index [J].Contemporary

[2] X.M. Wang. The Application of Multi-analysis [M] .Shanghai: Shanghai University of Finance and Economics press, 2014. (In Chinese)

[3] X.T. Zhang. Econometric E-views Guide [M].TianJing: Nankai University press, 2003. (In Chinese)

[4] Z.N. Li. Advanced Econometrics [M].Beijing: Tingshua University press, 2000 (In Chinese)

[5] L. Shen, Z.H. Dai. Empirical study on portfolio size, risk and return of Shanghai securities market [J] Journal of UEST of China, 2006(6) (In Chinese)

[6] X.L. Ma. The process of interest rate liberalization in China is viewed from the money market [J]. Guizhou institute of finance and economics, 2005(1) (In Chinese)

[7] Z.Y. Huang. The market analysis of the interest rate in China's inter-bank lending market [J].Shanghai Finance, 2003(11) (In Chinese)

[8] W.W. Cao. A review of the inter-bank lending rate in Shanghai [J].Times Financial, 2016(21) (In Chinese)

[9] Q.F. Liu, D.H. Zhou. The effect of economic policy on real estate stock index [J].New Finance, 2012(3) (In Chinese)

[10] Q. Li, H.Ma. Research on the relationship between interest rate, stock index, money supply and real estate price [J].Journal of Wenzhou University, 2013(4) (In Chinese)

[11] S. Yang. Empirical study on the correlation between interest rate, stock index rate of return and stock trading volume[J]. Shanghai university of finance and economics press, 2009 (In Chinese) 